\title{
Dispersão e etnicidade de um grupo amazônico: a sobreposição da REBIO Guaporé e a transformação dos Migueleno em colonos
}

Luiz Augusto Sousa Nascimento ${ }^{1}$ Instituto Federal de Educação, Ciências e Tecnologia do Maranhão

Resumo: O objetivo do trabalho é analisar os processos relacionais entre os indígenas Migueleno, o território e o Estado brasileiro na região do atual Estado de Rondônia. O SPI Pautado na teoria da aculturação, no ano de 1928, considerou os Migueleno como grupo extinto, alegando a sua integração à sociedade nacional. A partir desse período, parte do grupo passou a constituir moradia na Vila do Limoeiro, a margem esquerda do rio São Miguel, afluente do Guaporé. Em 1982, o Governo brasileiro criou a Reserva Biológica do Guaporé, deslocando os Migueleno e parte de seringueiros para um assentamento a margem direita no baixo São Miguel, classificando o grupo como "colonos assentados" pelo Instituto Nacional de Colonização e Reforma Agrária - INCRA. A partir do ano de 2000, os Migueleno através do movimento indígena estão reivindicando sua etnicidade e procurando caminhos para retornar ao seu território de "ocupação tradicional", atualmente sobreposto à Reserva Biológica do Guaporé. A pesquisa pautada em estudos etnográficos analisa os processos situacionais, a dispersão dos Migueleno e a relação deles com o território de "ocupação tradicional”, atualmente sobreposto por uma Reserva Biológica.

Palavras-chave: Migueleno, territorialização, Reserva Biológica do Guaporé 


\title{
Dispersion and ethnicity of an Amazonian group: the overlapping of REBIO Guaporé and the transformation of the Migueleno into settlers
}

\begin{abstract}
The objective is to analyze the relational processes between indigenous Migueleno, the Brazilian state and territory in the present State of Rondônia region. The SPI Dedicated to theory of acculturation, in 1928, considered the Migueleno as extinct groups, claiming their integration into the national society. From this period, part of the group now constitutes chalet in the village of Limoeiro, the left margin of the São Miguel. In 1982 , the Brazilian government created the Biological Reserve Guapore Migueleno and moving the rubber part of a settlement to the right margin on the lower São Miguel , classifying the group as " colonists settled " by the National Institute of Colonization and Agrarian Reform - INCRA . From the year 2000, the Migueleno through the indigenous movement are claiming their ethnicity and looking for ways to return to their territory of "traditional occupation" currently overlapped the Biological Reserve Guapore. Research grounded in ethnographic studies analyzes the situational processes, the dispersion of Migueleno and their relationship with the territory of "traditional occupation" currently overlapped by a Biological Reserve.
\end{abstract}

Keywords: Migueleno, territorialization, Guaporé Biological Reserve

\section{Dispersión y etnicidad de un grupo amazónico: la superposición de la REBIO Guaporé y la transformación de los Migueleno en colonos}

\begin{abstract}
Resumen: El objetivo del trabajo es analizar los procesos relacionales entre los indígenas Migueleno, el territorio y el Estado brasileño en la región del actual Estado de Rondônia. El SPI Pauta en la teoría de la aculturación, en el año 1928, consideró a los Migueleno como grupo extinto, alegando su integración a la sociedad nacional. A partir de ese período, parte del grupo pasó a constituir vivienda en la Vila do Limoeiro, a la margen izquierda del río São Miguel, afluente del Guaporé. En 1982, el Gobierno brasileño creó la Reserva Biológica del Guaporé, desplazando a los Migueleno y parte de los caucheros para un asentamiento a la margen derecha en el bajo San Miguel, clasificando al grupo como "colonos asentados" por el Instituto Nacional de Colonización y Reforma Agraria - INCRA. A partir del año 2000, los Migueleno a través del movimiento indígena están reivindicando su etnicidad y buscando caminos para retornar a su territorio de "ocupación tradicional", actualmente superpuesto a la Reserva Biológica del Guaporé. La investigación pautada en estudios etnográficos analiza los procesos situacionales, la dispersión de los Migueleno y su relación con el territorio de "ocupación tradicional", actualmente superpuesto por una Reserva Biológica.
\end{abstract}

Palabras clave: Migueleno, territorialización, Reserva Biológica del Guaporé 
$\mathrm{O}$ s Migueleno são etnograficamente identificados (HANSEMAN, 1912; NORDENSKIÖLD, 1913; NASCIMENTO, 2011; LIMA, 2011) como habitantes do território no vale do Guaporé-São Miguel. Foram contatados pelas frentes de atração colonial no início do século de XX. O encontro intersocietário entre indígenas e colonos reconfigurou a situação política do Grupo que a partir do contato com as agências coloniais passaram a ter o órgão indigenista oficial, Serviço de Proteção aos Índios (SPI) como referência para as negociações tangentes ao uso da terra, às relações comerciais, bem como o SPI passou conduzir os processos de territorialização ${ }^{2}$ do Grupo. Em 1928, pautado na perspectiva teórica do culturalismo estadunidense, o estado brasileiro, decretou a extinção dos Migueleno, alegando que o Grupo havia adquirido condições suficientes para ser integrados à sociedade nacional, pois a maioria dos membros do grupo passou a usar a língua portuguesa como a língua principal e para o SPI esse fator indicava a integração do grupo à comunhão nacional.

A partir desse período, os Migueleno passaram a conviver juntos com os seringueiros sob o auspício da administração colonial centrado no Posto Indígena "Treze de Maio", localizado as margens do rio Manuel Correa, afluente do rio São Miguel no território do atual estado de Rondônia na Amazônia brasileira. Parte de famílias domésticas de Migueleno passou a prestar serviços para os patrões seringueiros através do sistema de aviamento ${ }^{3}$ muito comum na região amazônica. Nesse contexto, inicia um processo de amalgamento entre o Grupo, intensificando o casamento entre mulheres Migueleno e seringueiros e a dispersão para as cidades circunvizinhas à região da bacia do Guaporé. Essa situação ocasionou perda relativa da autonomia territorial de "ocupação tradicional" do Grupo cujo controle territorial passa para as mãos dos colonos, sobretudo, os patrões que adquirem autorização legal para explorar as melhoras áreas de extração de seringa, monopolizando a comercialização deste produto e outras especiarias da floresta, tais como pele de animais, carne de caça, frutas e ervas medicinal.

Depois que o Serviço de Proteção aos Índios - SPI - desativou o Posto Indígena "Treze de Maio" em 1928, parte dos Migueleno passou a habitar a região da vila do Limoeiro, localizada à margem esquerda do rio São Miguel, permanecendo nessa localidade até o ano de 1982, quando o Governo Militar através do Instituto Brasileiro de Desenvolvimento Florestal - IBDF - criou a Reserva Biológica do Guaporé, desapropriando indígenas, descendentes de escravos ${ }^{4}$ africa-

\footnotetext{
${ }^{2}$ Territorialização aqui empregado se refere ao que OLIVEIRA (2004) trabalha para as análises dos grupos indígenas do território brasileiro.

${ }^{3}$ Para abordagem referente ao sistema de aviamento na Amazônia ver (PERES, 2004; 2003) e (NASCIMENTO, 2017).

4 Os Migueleno conviveram na área de "ocupação tradicional" com dois grupos de descendentes de escravos africanos. A comunidade rural "quilombola" do Jesus cuja área foi titulada pelo INCRA em 2009 e a comunidade rural "quilombola" Santo Antônio cuja área está em processo de Identificação. Respectivamente essas duas comunidades estão localizadas no baixo São Miguel e no médio Guaporé nas proximidades da foz do rio São Miguel.
} 
nos e seringueiros que habitavam parte de uma área na margem esquerda do vale do São Miguel.

Nesse contexto, os Migueleno foram assentados como colonos pelo INCRA no assentamento de Porto Murtinho, localizado à margem direita do baixo São Miguel. Outras famílias do Grupo migraram para as cidades de Costa Marques, Ji-Paraná, Guajará-Mirim e Porto Velho, quando passaram a viver na periferia, envolvidos no subemprego (empregadas domésticas, vigias, vendedores ambulantes, artesões entre outros).

A partir do ano de 2002, lideranças do movimento indígena de Rondônia tiveram contato com algumas famílias migueleno. Nesse mesmo ano, os Migueleno passaram a participar das assembleias indígenas regionais. Em 2005, o caíque Tanadi Migueleno protocolou na administração da FUNAI de Ji-Paraná, um documento reivindicando o reconhecimento étnico dos membros do grupo, bem como solicitava a criação de um Grupo de Trabalho - GT - para iniciar os estudos de identificação e delimitação de um território em que o grupo considerava de "ocupação tradicional". Parte significativa do território de "ocupação tradicional" que o grupo reivindicava, atualmente encontra-se sobreposto a Reserva Biológica do Guaporé.
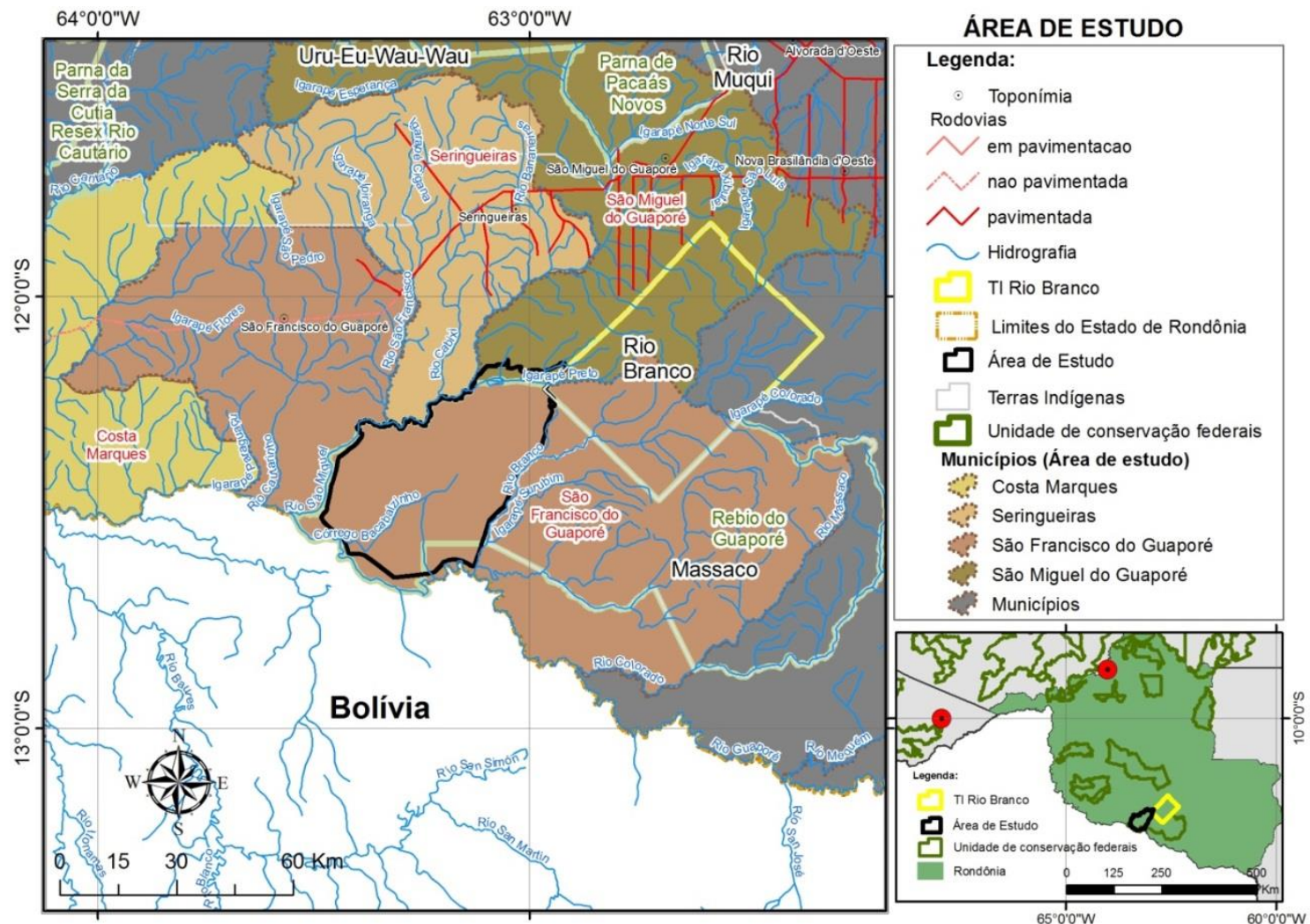

Fig. 1: Área da circunvizinhança do território de ocupação territorial dos Migueleno. Fonte: LIMA (2011)

Em 2008, a FUNAI coordenou um trabalho censitário e de informações antropológicas referentes aos Migueleno cujos resultados apontaram para o reconhecimento étnico do grupo, orientando para a constituição de um Grupo de Trabalho para realizar estudos de fundamentação antropológica. Nessa perspectiva, a região do baixo São Miguel tornou-se palco de conflito entre indígenas, fazendeiros e órgãos do poder executivo federal (INCRA, IBAMA, FUNAI e Polícia Federal). 
Como resultado das situações etnográficas, o artigo aponta as análises preliminares das relações entre os Migueleno e o estado brasileiro, o movimento indígena e os colonos assentados pelo INCRA, os conflitos gerados, a partir do momento em que os Migueleno passaram a reivindicar, através do movimento indígena, uma etnicidade e uma área considerada de "ocupação tradicional" possível para salvaguardar a reprodução física e cultural do grupo.

\section{Situações históricas e os processos de territorialização}

Os registros referentes à ocupação do vale do São Miguel datam desde o período em que os Jesuítas fundaram a missão São José no vale do Guaporé em 1769. Nas incursões ao São Miguel, os jesuítas fizeram menção ao contato que mantiveram com vários grupos indígenas, entre eles os Nambikwara, Gavião e grupos considerados arredios que não mantiveram contato, mas que era de conhecimento dos religiosos, como os Pawumwa [Migueleno?] e Tupari.

A região do vale do São Miguel no inicio do século XX era habitada por grupos indígenas que somente passaram a manter contato sistemático com os núcleos de povoamento colonial as margens do rio, quando o estado brasileiro passou a intervir na região, instalando posto de atração para a "pacificação" de grupos considerados arredios e para amenizar os conflitos protagonizados por grupos indígenas e seringueiros.

As narrativas confirmam que no inicio do século XX, entre os grupos do vale do São Miguel, os Migueleno foram um dos grupos que mantiveram constantes encontros com os seringueiros cujos resultados desses encontros representaram para o Migueleno, uma baixa populacional, ocasionadas pelo contágio de doenças como sarampo e gripe. Com a redução populacional e a perda do domínio territorial, os Migueleno procuraram aliança com os Cabixi que habitavam a região da foz do rio São Francisco, afluente da margem direita do São Miguel. A história oral confirma que muitas mulheres pertencentes ao grupo realizaram alianças matrimoniais com seringueiros, permanecendo na região, porém desagregadas da vida diária mais ampla do conjunto do Migueleno.

Meu avô me contou que o nosso grupo veio subindo o rio São Miguel fugindo dos se-
ringueiros e de outras tribos que atacavam nosso povo. Muitos morreram de doen-
ças, principalmente as crianças e os mais velhos que não aguentavam. As mulheres
mais novas eles [os seringueiros] carregavam e aí, os pais nunca mais encontra-
vam. Quando o meu avô se entendeu, já bom de memória, nosso povo já estava no
São Miguel, já conhecia o Posto [Treze de Maio]. Aí foi se juntando com outras tri-
bos, foi se juntado no Posto, foi trabalhando para os civilizados e depois foi acaban-
do com nossas malocas e o povo foi misturando e vivendo parecido com os cristãos,
brincava nas festas do cristão lá no Limoeiro. (David Lima, indígena migueleno.
Guajará-Mirim, o3 de setembro de 2010; comunicação pessoal)

O primeiro registro etnológico e historiográfico referente aos Pawumwa ou Migueleno é de 1907, quando o naturalista J. D. Hanseman iniciou uma expedição científica na região nas matas sul-americana e nessa ocasião, encontrou na foz do São Miguel um grupo de indígenas sendo identificados primeiramente como Pawumwa. Hanseman publicou em 1912, um artigo na revista American Anthropologist. No artigo, Hanseman enfatiza que os Pawumwa [Migueleno] eram desconhecidos da comunidade científica e viviam em condições com pouca ou nenhuma afetividade com a civilização do homem branco. Ele chamou a atenção para os perigos que esses índios corriam devido à expansão dos seringueiros na região em que habitavam [baixo São Miguel]. O zoólogo enfatizou que a região da foz do rio São Miguel e o rio Guaporé era considerada na época, 
uma área habitada por grande quantidade de indígenas e que os brasileiros quando exploravam a região, seja estabelecendo moradias seja abrindo estradas ou explorando, as áreas de seringais sempre foram consideradas temerosas devido à presença indígena, mas o empreendimento colonial venceu a força dos indígenas. Também, os próprios seringalistas reconhecem a existência de indígenas na região e revela o quanto a região era conflituosa.

\begin{abstract}
Tinha índios no Guaporé? Tinha, mais..., era mais difícil. Mas aí, acima de GuajaráMirim. Aí era o berço deles? Aí sim, aí era o local, eles matavam. Se entrasse aí... Era difícil ele se saí. Se entrasse embarcações eles flechavam, eles tinham esses lugares, aqueles barrancos altos, na espera, eles flechavam. O rio era cheio de curvas... Era assim, assim, igarapé, eles ficavam amoitado aí. Quando a embarcação ia passando, eles metiam flecha para cima, flechavam nego... Matavam, flechavam, degolavam, faziam tudo que eles entendiam. Agora aqui de Guajará, do Mamoré prá cá, era mais difícil. Até a boca não, esse trecho era mais difícil. Eles viviam longe, sabe? Dá boca do rio, sabe? Tinham a aldeia deles, mas era mais longe, vamos dizer o Cautário, viu, tinha aldeia? Tinha, tinha aldeia, mas não era na beira, mais era mais longe, do Cautário, São Domingo, São Miguel. Aí também era uma aldeia grossa, aí tinha muito índio que não era brincadeira não. Aí o pessoal trazia os índios prá baixo prá não criar confusão [...]. (Seu Arlindo, encontrado em www.historiaderondonia.com.br)
\end{abstract}

Em 1912, o governo brasileiro autorizou uma expedição ao vale do Guaporé/São Miguel sob o comando do Marechal Cândido Mariano Rondon cujo objetivo era pacificar índios arredios que estavam entrando em conflito com seringueiros. Sete anos após a passagem da expedição do marechal Rondon, ocorreu à fundação em 1919 do Posto Indígena Três de Maio, que os Migueleno se referem como sendo o Posto Colônia. O Posto Três de Maio foi instalado na região com o objetivo de realizar a "pacificação" e a "proteção" dos indígenas no sentido de apaziguar os constantes conflitos existentes na região.

A partir desse período, parte dos membros do Grupo passou a conviver com outros grupos indígenas, principalmente os Cabixi no baixo São Miguel, bem como parte do Grupo foi atraído para o Posto Três de Maio, quando este era inspecionado pelo funcionário José Félix do Nascimento. A pesquisa aponta que nos primeiros anos de funcionamento do Posto Três de Maio, havia aglutinados cerca de 150 índios Puruborá e Gavião. Posteriormente chegaram os índios Cabixi e os Migueleno, originários do rio São Miguel. Esses índios trabalhavam para o encarregado do Posto, o senhor José Félix do Nascimento, que lhes forneciam mercadorias em troca de seringa. José Félix do Nascimento incentivava e patrocinava casamentos interétnicos entre indígenas e seringueiros, assim como comercializava com índios e seringueiro através do sistema de aviamento, muito comum na região amazônica.

O período compreendido entre as décadas de 1950 a 1970, a região do vale do São Miguel foi palco de muitos conflitos envolvendo vários atores locais. Também nesse período, a ação missionária intensifica na região com o propósito de levar a "civilidade" aos índios e amenizar os conflitos causados pelo projeto de colonização do Território Federal do Guaporé. Sobre a ação missionária temos a seguinte referência: Ofício do Ministério da Agricultura de 1951 do Diretor do Serviço de Proteção aos Índios, senhor Modesto Donatini da Cruz, encaminhado ao chefe da nona Inspetoria Regional, atestando os trabalhos missionários que irão ser realizados na região do rio São Miguel sob a coordenação do bispo D. Francisco Xavier Rey, bispo prelado de Guajará-Mirim: "Levar vantagens da civilização aos indígenas” (Microfilmes 243/51).

Documentos e correspondências oficiais relatam com veemência a situação conflituosa na região do vale do São Miguel. No Ofício número 29/1967 do chefe 
do policiamento de fronteira, trata do encaminhamento de um relatório elaborado pelo chefe substituto da nona Inspetoria do SPI, senhor José de Mello Fiúza, atestando conflitos entre índios e civilizados na região.

Nesse contexto, os indígenas que habitavam a região do vale do São Miguel foram perdendo espaço territorial para os colonizadores. Muitos grupos foram reduzidos a pouco menos de dez pessoas como aponta o relatório elaborado em 1968 pela missionária do Summer Institute of Linguistics Carolyn Bontkes. Bontkes relata que no ano de 1968 na região do São Miguel só havia pouco índios, mas reconheceu que havia "tribos bravas nas cachoeiras". No mesmo relatório, Bontkes aponta que encontrou somente cinco índios na região do baixo São Miguel, sendo quatro Cabixi e um Puroborá. Todavia, temos que observar o prisma do entendimento de índio que a missionária toma como referência, pois tudo leva a crer que ela está pautada na visão culturalista, ou seja, os indígenas no seu estado de "conservadorismo".

Sobre a história do último indígena Cabixi enfatizado pela missionária, o cacique Tanadi Migueleno assevera que quando os Cabixi foram pacificados pelo SPI passaram a conviver com os Migueleno e os civilizados na localidade de Limoeiro até o ano de 1981 quando o governo federal desapropriou a área, transformando parte do território de "ocupação tradicional" dos Migueleno em Reserva Biológica.

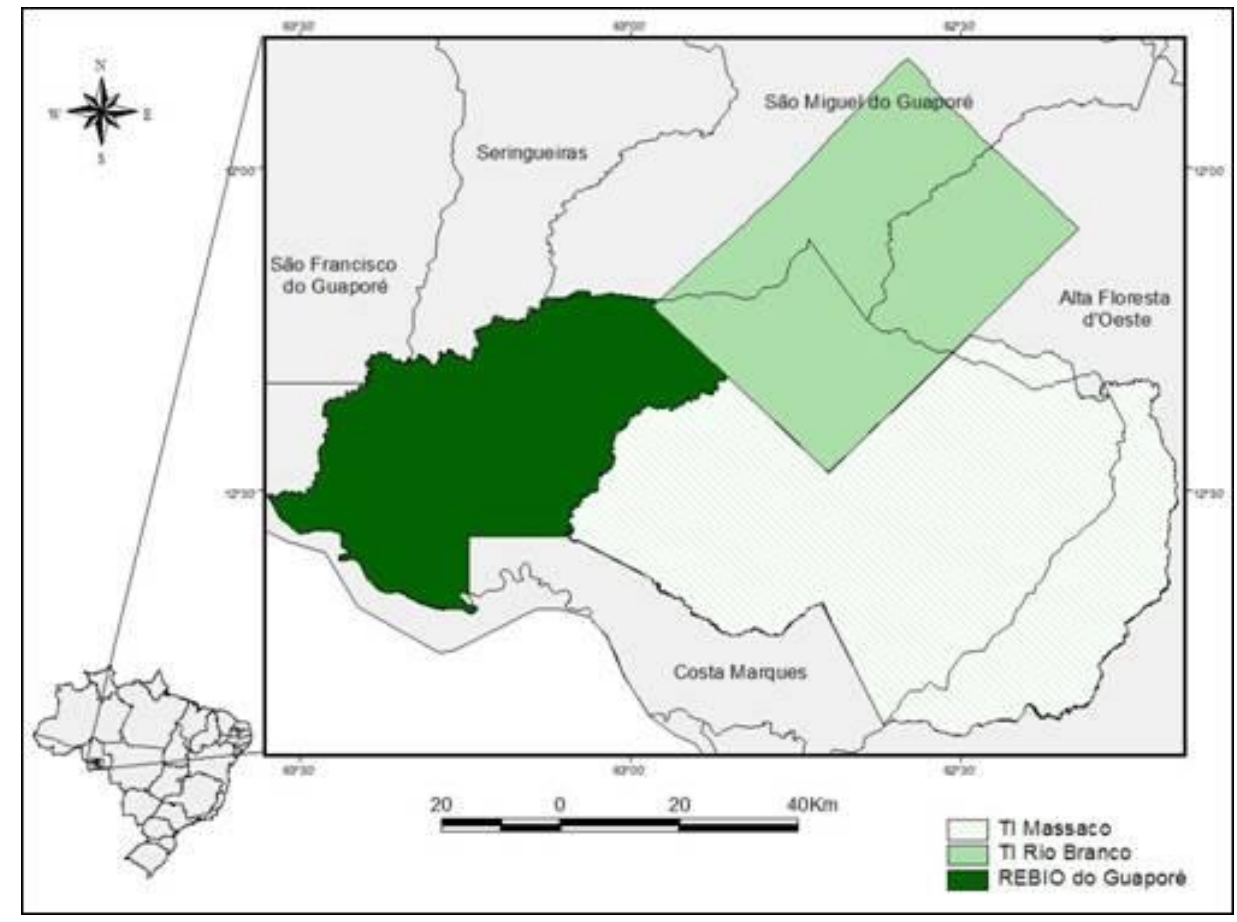

Fig. 2: Reserva Biológica do Guaporé e as Terras Indígenas. Fonte: NASCIMENTO (2011)

Os Migueleno e todos os grupos humanos ali habitados foram deslocados no ano de 1982, para o Assentamento Porto Murtinho, localizado à margem direita do São Miguel na localidade denominada de Nova Olinda, hoje Porto Murtinho. De acordo com as narrativas, Nova Olinda foi um povoamento fundado em 1925 por um seringalista chamado Ciriáco de Freitas que foi patrão dos Migueleno durante muito tempo. O filho do Ciriáco de Freitas, seu Ursulino de Freitas casou-se com dona Iria de Freitas uma índia identificada pela FUNAI como pertencente ao grupo étnico Migueleno, quando na verdade pertence ao 
grupo étnico Tupari, mas que convive com os Migueleno desde os tempos em que o grupo habitava a vila do Limoeiro.

No período de 1982 a 2000, os Migueleno dispersaram para as principais cidades circunvizinhas do seu território de "ocupação tradicional”: GuajaráMirim, Ariquemes, Costa Marques e Porto Velho. As famílias que permaneceram em Porto Murtinho foram se associando com grupos de colonos assentados pelo INCRA, recebendo lotes de terras de 17 a 21 hectares; fomento e assistência técnica para práticas agrícolas e agropecuárias.

Com o advento da Constituição Brasileira de 1988, o movimento indígena de Rondônia e as organizações indigenistas, principalmente o Conselho Indigenista Missionário - CIMI- impulsionaram os grupos étnicos ${ }^{5}$ que se encontravam em situações de "desterritorialização" a repensar as questões relacionadas às terras tradicionalmente ocupadas por "povos originários". Esse contexto vai impulsionar a primeira assembleia do grupo Migueleno para discutir a identidade, etnicidade, direitos constitucionais e, a partir de então, solicitar da FUNAI, o reconhecimento étnico e o direito ao território tradicionalmente ocupado pelo grupo, ou seja, o território que hoje está protegido pelo IBAMA sob o auspício de uma Unidade de Conservação - REBIO Guaporé.

\section{Os Migueleno, o território e o movimento indígena}

Quando os Migueleno organizaram sua primeira assembleia junto com o grupo Puruborá ${ }^{6}$, decidiram reunir todos daqueles grupos que se encontravam dispersos pelas periferias das cidades, a fim de iniciar um processo de solicitação para o órgão indigenista oficial que considerasse os membros do grupo como indivíduos etnicamente diferentes do conjunto maior da sociedade nacional, sobretudo, eles passaram a buscar elementos ${ }^{7}$ da cultura material (urnas funerárias $^{8}$, cemitérios, antigas malocas etc.) que comprovassem ${ }^{9}$ que o seu território de "ocupação tradicional" em uma área localizada a margem esquerda do rio São Miguel que hoje está sobreposta a Reserva Biológica do Guaporé.

Durante a década de 2000, o movimento indígena com o apoio das organizações indigenistas organizou vários encontros com lideranças indígenas, gestores do Estado, Ministério Público, parlamentares com o objetivo de demonstrar o quanto a colonização do estado de Rondônia desordenou o espaço territorial dos grupos indígenas, tornando a questão fundiária um problema na região. Também nos anos 2000, ocorreu a "insurgência" de grupos étnicos que foram silenciados durante décadas e conduzidos a esconder suas "identidades", desvinculando sua relação com o "território", sendo ignorados pela perspectiva da política indigenista do estado brasileiro que passou a considerar os grupos étni-

5 Utilizo a noção de grupo étnico no sentido de Barth (1998).

${ }^{6}$ Os Puroborá são povos que conviveram com os Migueleno na região das confluências dos rios Manuel Correa e São Francisco, ambos afluentes do rio são Miguel. A situação fundiária dos Puruborá é semelhante a dos Migueleno, porém há duas sobreposições no território em que o grupo considera de "ocupação tradicional”: sobreposição da Terra Indígena Uru-Eu Wau-Wau e a Reserva Biológica do Guaporé.

7 O grupo passou a considerar uma gama de objetos da cultura material como pertencentes aos seus antepassados. Urnas funerárias encontradas dentro do território de "ocupação tradicional" foram classificadas como pertencentes ao grupo; os locais das antigas malocas passaram a ser considerados como locais sagrados entre outros elementos que os Migueleno resignificam como parte da sua cultura para compor a sua política étnica. Sobre a questão da política étnica dos Migueleno ver NASCIMENTO (2011).

8 Essas urnas funerárias têm um valor heurístico para os Migueleno/Huanyam. Eles tomam consciência que elas representam um recuo histórico da ocupação da região amazônica. Todavia, a ideia não é percorrer pela ciência arqueológica para qualificar o valor de pertencimento dessas urnas, mas considerar como a coletividade migueleno está se apropriando das mesmas; como eles interpretam e pensam sobre essas urnas funerárias encontradas na região da área de "ocupação tradicional' do grupo, bem como, a significância desses artefatos histórico/arqueológicos representam para a vida dessas pessoas". 
cos em contato sistemático com a sociedade como integrados à comunidade nacional, portanto não mais merecedores de manter vínculo com um "território" demarcado, homologado com usufruto exclusivo que garanta a sobrevivência física e cultural, como assegura a Constituição Brasileira vigente.

A antropologia contemporânea de Oliveira (1999), Little (2002), Souza Lima e Barreto Filho (2004), considera território como sendo uma área determinada na qual uma coletividade exerce suas práticas de reprodução física e cultural. Tratando-se de populações humanas, o território é um produto de construção histórica de um determinado grupo, realizado a partir do trabalho e da identificação dos espaços como sendo inerentes às formas adotadas pela população nele residente para o uso e usufruto. Assim, o território possui diversas dimensões, tais como a física, cultural, econômica, social, religiosa entre outras.

Nesse contexto de "indianização" dos Migueleno ou a reconstrução de uma etnicidade, a questão do "território" passa a ser a pauta integrante dos encontros dos membros do grupo com representantes do Estado, da sociedade civil e do Ministério Público Federal que passa a pressionar o órgão indigenista oficial, a garantir a realização de estudos que venham a fundamentar e legalizar a área de "ocupação tradicional" para o grupo, área esta que está sobreposta à Reserva Biológica do Guaporé. Desde 2011, quando a FUNAI instaurou o GT Migueleno de Fundamentação Antropológica, não ocorreram avanços significativos que apontem para a garantia do território que o grupo reivindica. Os relatórios ambientais e antropológicos foram entregues à Coordenação Geral de Identificação e Demarcação, entretanto, até o final da escrita do artigo, não obtivemos orientações do órgão indigenista sobre os trâmites dos estudos.

\section{Chefia e política: o cacicado e o associativismo como instrumentos de políticas étnicas}

Os grandes chefes entre os Migueleno são apontados pela literatura específica Hanseman (1912), Nordenskiöld ([1913] 2001) como pessoas que desempenhavam papeis sociais específicos, tais como a coordenação dos rituais e a proteção espiritual das pessoas. O controle político e os processos das relações intersocietárias se concentravam nas mãos dos chefes de famílias extensas que além de possuir o poder sobre seus entes consanguíneos e afins mantinham grandes influências nas tomadas de decisão do grupo quando se tratava de questões que ultrapassavam as fronteiras das "malocas".

Como os processos das relações intersocietárias são dinâmicos, o grupo foi ampliando novas estratégias de se organizar politicamente. Peres (2004) passou a categorizar o movimento indígena como política étnica, quando os indígenas passaram a se familiarizar com uma gama de questões relacionadas aos direitos indígenas se inserindo em uma série de mecanismos políticos tais como as associações indígenas estatutárias para dialogar com o Estado brasileiro e outras instâncias da sociedade civil.

$\mathrm{Na}$ atual conjuntura, entre os Migueleno, o chefe que recebe o nome de "cacique" é indicado em assembleia para representar o grupo no âmbito da política exterior; seja no movimento indígena seja com as instâncias do Estado e da sociedade civil. Todavia, internamente, o "cacique" não detém todos os poderes. As tomadas de decisões têm que ser levadas para a assembleia, haja vista, que os chefes de famílias extensas durante as assembleias são quem decidem e têm o poder de destituir a qualquer momento o "cacique". Não há um estatuto para reger a permanência de um "cacique" no cargo. Os chefes das famílias extensas 
também são os responsáveis pela administração e gestão das Associações estatutárias, presentes no mundo indígena como elemento articulador entre grupos étnicos e o Estado.

Associação estatutária é um fenômeno recente entre os Migueleno. Com o reconhecimento pela Constituição Federal de 1988 do direito dos grupos indígenas e suas organizações de se fazerem representar diretamente aos tribunais e perante o Estado Brasileiro, seu antigo tutor, começou a deflagrar a expansão do associativismo como forma privilegiada de mobilização e organização política da etnicidade. Peres (2004), que estuda a questão do "associativismo" na Amazônia brasileira, enfatiza que com o associativismo ocorreu à culminância de um fenômeno de transformação do estigma da ancestralidade nativa em orgulho étnico, de recuperação moral da etnicidade indígena como elemento positivo de construção social do self individual e coletivo.

\begin{abstract}
Entendo o fenômeno associativismo indígena como um desenho participativo, horizontal e descentralizado de implementação de políticas étnicas de mobilização coletiva, mas também altamente formalizado (diretoria, conselho fiscal, assembleia) e depende mesmo de uma base cartorial (registro no Cadastro Nacional de Pessoa Jurídicas/CNPJ) enquanto modalidade de reconhecimento oficial, e de assessoria profissional como condições de acesso a redes de cooperação internacional. (PERES, 2004, p. 22-23)
\end{abstract}

Foi através da associação e do movimento indígena que os Migueleno começaram a desenvolver uma política de etnicidade e pela busca de um território considerado por eles como de "ocupação tradicional".

Desde o ano de 2000, os Migueleno fazem parte de três associações estatutárias locais (Associação dos Comunitários de Porto Murtinho; Associação dos Assentados do Projeto Limoeiro e Associação das Mulheres Agricultoras de Porto Murtinho). Também fazem parte de coordenação em nível regional como a Coordenação da União das Nações e Povos Indígenas de Rondônia, Noroeste de Mato Grosso e Sul do Amazonas - CUNPIR - e de uma coordenação em nível nacional, a Coordenação das Organizações Indígenas da Amazonas Brasileira COIAB, além de algumas pessoas fazerem parte da Colônia dos Pescadores da cidade de São Francisco do Guaporé cujo coordenador local em Porto Murtinho é um índio Puruborá.

O grupo controla a participação dos seus membros nessas instituições, indicando, elaborando pauta e fazendo pressão para que sejam atendidas suas demandas no campo da política intersocietária. Para Oliveira (2004) no campo intersocietário os eventos da política moderna sejam eles promovidos pelos órgãos indigenistas, por entidades religiosas ou de apoio aos índios, ou até mesmo pelas diferentes formas do chamado movimento indígena - recebem e são convertidos aos parâmetros da política étnica local, que ele denomina de "etnopolítica”.

\begin{abstract}
As manifestações simbólicas dos índios atuais estarão marcadas por diferentes tradições culturais. Tais elementos culturais constituindo-se em fato corriqueiro a adaptação de pautas culturais ao mundo moderno e globalizado. A incorporação de rituais, crenças e práticas exógenas significa que operadores externos são ressemantizados e fundamentais para a preservação ou adaptação de uma organização social e um modo de vida indígena. As unidades sociais abandonam velhas formas culturais, recebem ou reelaboram algumas de outras sociedades e ainda criam formas novas distintas. (OLIVEIRA, 1998, p. 68)
\end{abstract}

Portanto, as associações indígenas são aparatos com os quais os Migueleno vêm operacionalizando no mundo contemporâneo e, justamente com a força das famílias extensas conduzem a política local. No entanto, pela dispersão de parte 
dos Migueleno pela periferia das cidades rondonienses, as associações não conseguem ou não afiliaram todos os membros do grupo, haja vista, existirem problemas internos entre os Migueleno no que diz respeito à "indianidade" das pessoas que não habitam o espaço territorial de Porto Murtinho, onde a maioria dos membros do grupo está aglutinada, pois de acordo com o cacique Tanadi Migueleno, as pessoas que migraram para as cidades se distanciaram do "ser migueleno" e do território. Os argumentos do "cacique" resumem a organização social do grupo e os processos da "etnopolítica" que são defrontados no dia a dia:

\begin{abstract}
Nós Migueleno hoje não estamos todos unidos. Uns foram para as cidades, outros são funcionários do Estado e muitos continuaram aqui próximos do território que nossos avôs e nossos pais nasceram e trabalharam. O povo de Porto Murtinho [Migueleno] ainda tem uma relação com o Território do Limoeiro. Nós somos proibidos de entrar em nosso antigo território pela o IBAMA, mas mesmo assim a vontade é grande e acabamos desrespeitando as ordens oficiais. Mas é porque meu cordão umbilical e de muitos da minha geração está enterrado nessas terras [REBIO] por isso a insistência de permanecer aqui. Sou cacique, mas me vejo enfraquecido com essa situação. A comunidade me dá poder para conversar sobre a terra com o Governo, mas as coisas são difíceis. O movimento indígena me reconhece como liderança e as autoridades também. Conheço os vereadores de São Francisco, conheço o prefeito e sou funcionário da prefeitura. Então tenho que saber conversar porque estou em muitos campos políticos. Os Migueleno hoje não estão morando em malocas, mas estamos aqui organizados do nosso jeito em Porto Murtinho, convivendo com outros povos, mas isso foi o próprio Governo que incentivou. Aqui em Porto Murtinho tem Puruborá, tem Tupari, tem Macurape, tem quilombola, mas nós sabemos se diferenciar quando for a hora. Agora é esse que é o nosso jeito. (Cacique Juscinaldo Cardoso Tanadi, Ji-Paraná, 07 de dezembro de 2010)
\end{abstract}

\title{
Território: espaço de construção coletiva
}

A noção de "território" pelo viés da perspectiva etnológica é construída por uma coletividade a partir de concepções históricas, sociológicas, cosmológicas e de uma ampla rede de relações sociais e de parentesco. Little (2002) considera que o território é o resultado da percepção de um esforço de uma coletividade em ocupar, usar, controlar e se identificar com o espaço biofísico em que residem e sobrevivem. A territorialidade se expressa de formas múltiplas, com variações e particularidades socioculturais tais como os saberes etno-ambientais, as identidades sociais formadas a partir da identificação com o espaço/território de vivência, regimes de produção e posse das terras, histórico da ocupação espacial e territorial, suas formas de defesa e perpetuação, além de outras. 


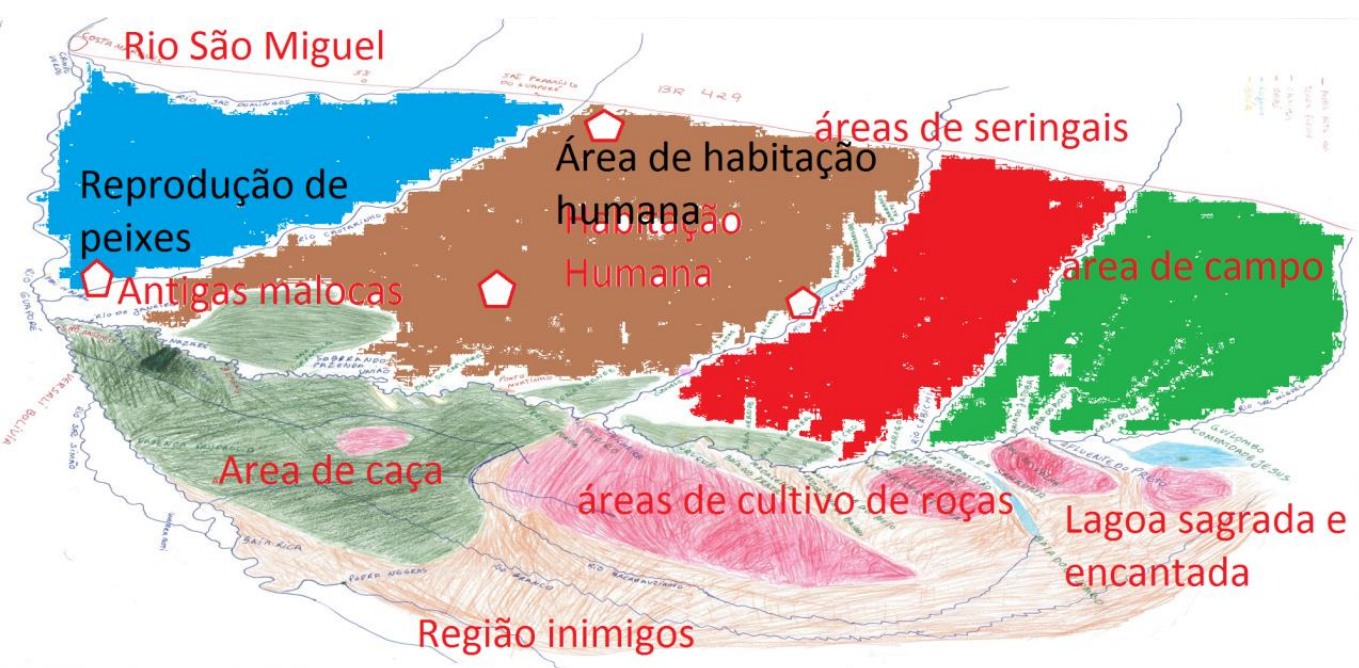

Elaboração e concepção do território do Migueleno: Elaborado na Oficina em Porto Murtinho. Dezembro de 2010. Participação dos alunos Darlan Silva, Isadora Cardoso Migueleno, Nicinha Migueleno e Elias Migueleno e Tanadi Migueleno.

Fig. 3: Fonte: NASCIMENTO (2011)

Oliveira e Santos (2003) enfatizam que o procedimento de buscar legitimidade da posse dos grupos indígenas sobre determinados territórios apelando para a antiguidade dessa ocupação não é de forma alguma coerente com os termos da atual Carta Constitucional, que conceitua "terra indígena" a partir da noção de "ocupação tradicional", e não a ideia de "imemorialidade". Os Migueleno demonstraram dúvidas quanto à importância dessa questão quando passaram e reconstruir seu território, no entanto enfatizam a imemorialidade no sentido de construir narrativas sobre o território e não na insistência de buscar a sua "essencialidade".

As terras indígenas a partir da concepção do Art. 231 da Constituição Federal são definidas como aquelas ocupadas pelos indígenas, isto é, aquelas que são utilizadas segundo seus "modos", "usos" e "costumes" - o que é diferente, portanto, de terras imemoriais, que remetem de forma necessária à demonstração da antiguidade e continuidade da ocupação indígena. De acordo com o antropólogo João Pacheco de Oliveira (2004), não é necessário que essas populações vivam ainda hoje fora do sistema de mercado, da malha fundiária ou das religiões ocidentais, mas que se concebam como descendentes de populações originárias que aqui [no território de ocupação tradicional] vivem (OLIVEIRA, 2004, p. 109).

Dessa maneira, os Migueleno têm a consciência que o território que hoje eles consideram como de "ocupação tradicional" que está sobreposta a Reserva Biológica do Guaporé é construído a partir das noções coletivas de "uso", "ocupação" e espaços socioculturais e que fizeram parte da vida deles no passado e que hoje é necessário para a vida do grupo no presente e indispensável para a vida do grupo no futuro. Essa situação foi enfatizada pelo ancião David Aranha Migueleno:

Eu sei que meus bisavôs nasceram no São Miguel, trabalharam e criaram seus filhos naquele lugar. Sei também que eles andaram por outros lugares, pois o senhor [eu] sabe, que índio não se ficar parado em um só lugar por muito tempo; antigamente meu avô contava que não passava muito tempo em um só lugar, vivia igual macaco, senhor [eu] saber, macaco é bicho que vive pulando de galho em galho não se aquieta mesmo. Mas isso é bom. Nós conhecemos pedacinho por pedacinho do São Miguel. Lá estar à vida de todos nós Migueleno, as baias, os locais de roça, os 
seringais, os castanhais, o campo bom para caçada e tudo. Já morei e tralhei com a minha família em várias localidades, trabalhei no Centro [localidade na margem esquerda do São Miguel] na labuta da castanha, trabalhei no Limoeiro, na Andorinha tirando seringa, então essa região sustentou meus avôs, meus pais. Agora eu não posso sustentar todos os meus filhos lá, porque o Governo não deu condições para isso e acabou expulsando nós de lá. Mas todos os meus filhos nasceram lá no São Miguel. Tenho dois filhos lá no Porto Murtinho, que não vão sair de lá não. Eles precisam criar os filhos deles com o sustento do São Miguel. (David Aranha Migueleno, Guajará-Mirim, o1 de maio de 2011)

Portanto, os Migueleno visualizam a questão do território de "ocupação tradicional" como valorativo da vida dos Migueleno do passado e representativo da vida do grupo no presente e, dessa maneira, consideram que deve ser reconhecido o "território" deles como objeto de direito, onde eles [Migueleno] lançam mão de múltiplas estratégias adaptativas, tenta de algum modo preservar valores por eles partilhados, construindo uma sociabilidade e um projeto de futuro calcado em sua peculiar relação com o passado.

Nessa perspectiva, o território de “ocupação tradicional” dos Migueleno é fruto de uma ação social expressada pelos membros do grupo quando apoiados na consciência coletiva, passam a afirmar e reivindicar uma identidade ${ }^{10}$ e consequentemente o território que o grupo considera como necessário para a garantia da vida física e cultural dos membros do grupo. Essa situação é resumida pelo cacique do grupo da seguinte forma:

\begin{abstract}
Eu digo uma coisa para você [eu]. Aqui a maioria das pessoas conhece bem os lugares de onde tirar seu sustento, assim como sabem muito bem onde estão enterrados seus cordões umbilicais. Aqui era de costume nosso [Migueleno/Huanyam] quando uma pessoa nascia os pais enterravam o umbigo da criança no quintal para marcar que essa é a terra de onde você nasceu e que pode ali morrer ou ser sepultado. Isso é muito forte para o nosso povo. Tem tantas coisas nessa área que os Migueleno necessitam para viver. Uma delas é esse rio São Miguel. É daqui que tiramos boa parte do nosso sustento. É no São Miguel que temos nossas praias que usamos para divertimento e para pescar também. As praias também são ambientes dos bichos de cascos, que usam as praias para desovar. Tem a Castanheira lugar bom para a labuta de roça, tem o campo que nos dar caça. As pessoas reconhecem esses lugares não somente pelo modo de usar, mas também muitos desses lugares nos fazem lembrar as pessoas mais velhas que moravam com a gente, como o Dolores, o Piá, o Firmino. Então essa área que consideramos nossa não é uma invenção de uma só pessoa, assim com não é uma invenção que parte do nada. Não, não é isso não! Temos a consciência que não estamos tomando nada de ninguém, mas lutando para ter um território que meu avô trabalhou, morou e morreu e hoje os filhos e netos estão aqui também para trabalhar e morar. Com a demarcação da nossa Terra teremos a liberdade para controlar e proteger os recursos naturais e cultivar as nossas roças. Veja como se encontra parte do nosso povo que estão morando em GuajaráMirim? Estão expostos a vida nas drogas, à prostituição e morando na periferia sem a mínima condição de uma vida digna. Aqui no São Miguel eles terão outra vida. (...). (Cacique Tanadi, Porto Murtinho, 25 de abril de 2011)
\end{abstract}

\title{
Considerações
}

Do ano de 2000 até os dias atuais, pelo viés da política local do movimento indígena ou da "política étnica”, os Migueleno realizaram dez assembleias, reunião com representantes do poder público, com a agência indigenista oficial entre outras instituições do terceiro setor, a fim de demonstrar para o Estado brasileiro a importância da regularização do território que eles consideram como de "ocupação tradicional" alicerçado nos processos de "uso", "ocupação" e perten-

${ }^{10}$ Toda identidade é situacional, ou seja, seu uso depende de contextos históricos e varia de acordo com os diferentes segmentos de uma população (OLIVEIRA, 2004, p. 173). 
cimento identitário do grupo às populações pré-colombianas como reza a Constituição Federal Brasileira. Dessa maneira, o grupo manteve sua opção pela via étnica (indígena). Os Migueleno estão mobilizados através de sua organização social e política, participando ativamente do movimento indígena brasileiro. A partir do ano de 2004 eles passaram a ser assistidos pelos programas e políticas públicas relativas à educação escolar e à saúde indígena numa perspectiva diferenciada para povos indígenas. Também, a partir da mobilização étnica iniciada no início do ano de 2000, os Migueleno passaram a receber assistência por parte da agência indigenista oficial - FUNAI.

Os dados apresentados, respaldados na pesquisa etnográfica, demonstraram que os relatos sobre o passado dos Migueleno são congruentes com o processo de ocupação e colonização da região em que o grupo indica estar historicamente inserido. A consciência coletiva do grupo considera a região do Baixo São Miguel como sendo o território de "ocupação tradicional”, considerando o rio São Miguel como um patrimônio socioambiental dos mesmos. Isso ficou evidente nos relatos apresentados por diversos sujeitos locais, tais como anciãos, lideranças e outsiders que convivem e conviveram com os Migueleno durante o processo de ocupação colonial da região quando os Migueleno e outros grupos étnicos do vale do São Miguel passaram por processos de desterritorialização em decorrência das frentes de expansão extrativista da seringa e a frente de expansão ocupacional das terras amazônicas via projetos de assentamento subsidiado pelo Governo Federal a partir dos anos de 1970 e 1980.

A intenção não foi procurar provas historiográficas que permitissem confirmar os referidos relatos, mas antes ressaltar que, embora os relatos expressassem uma experiência histórica particular, configurando necessariamente uma versão distinta sobre o passado local, não demonstraram incompatibilidade ou incongruência com as fontes consultadas sobre a história de ocupação e exploração do vale do Baixo São Miguel. Dessa maneira, os Migueleno demonstraram o quanto à região do Baixo São Miguel é indispensável para a reprodução física e cultural do grupo e o movimento das organizações indígenas e a política étnica local são fatores constitutivos para vislumbrar caminhos para as proposições que eles almejam: reconhecimento étnico e garantia do território de “ocupação tradicional” que ficou sobreposto à Reserva Biológica do Guaporé.

Recebido em 05 de fevereiro de 2018.

Aprovado em 14 de agosto de 2018. 


\section{Referências}

BONTKES, Willem. Relatório de viagem ao Rio São Miguel. Mimeografado, SIL, 1968.

HASEMAN, J. D. Some notes on the Pawumwa Indians of south America. American Anthropologist, Columbia University Press, New York City, 1912.

LIMA. Artema Santana. Caracterização dos recursos naturais da área denominada de ocupação Migueleno habitada pelo povo indígena Migueleno. Unesco/Funai, Brasília, s/n, 2010.

LITTLE, Paul. Territórios sociais e povos tradicionais no Brasil: por uma antropologia da territorialidade. UnB/DAN, Série Antropologia, 322, Brasília, 2002.

MEIRELES, Denise M. Os guardiões da floresta: rio Guaporé no século XVII: Editora Vozes, Petrópolis, 1989.

NASCIMENTO, L. A. S. Patrões, Fregueses e donos: Economia e xamanismo no Médio Rio Negro. Tese de doutorado. PPGAS, Universidade Federal de São Carlos, São Carlos, 2017.

NASCIMENTO, L A S. Documento técnico preliminar de fundamentação antropológica necessário para compor os estudos de identificação e delimitação da TI Migueleno com os anexos que se fizerem necessários e demais informações relevantes para a realização de estudos complementares. UNESCO/FUNAI, Brasília, s/n, 2011.

NASCIMENTO. L A S. Plano de trabalho para os estudos de fundamentação antropológica da área denominada Migueleno. Mimeografado, Brasília, FUNAI, UNESCO, 2010.

NORDESNKIÖLD, E. Los Huanyam. Exploraciones e Aventuras em sudamérica, APCOB, La Paz, pp 309-329, 2001.

OLIVEIRA FILHO. João Pacheco de \& SANTOS, Ana Flávia Moreira. Reconhecimento étnico em exame. Dois estudos sobre os Caxixó. Rio de Janeiro, Contra Capa, LACED, 2003.

OLIVEIRA, João Pacheco de. Ensaio em Antropologia e História. Editora da UFRJ, Rio de Janeiro, 1999.

PERES, Sidnei. Cultura, política e identidade na Amazônia: o associativismo indígena no Baixo Rio Negro. Tese de doutorado. UNICAMP. IFCH, Campinas, SP, 2003.

PERES, Sidnei. O diálogo intercultural como espaço e instrumento da nova cidadania indígena. 24 RBA, Recife, 2004.

PINTO, E. Roquete. Rondônia. Segunda Edição. Rio de Janeiro. Impressa Nacional, 1919.

SOUZA LIMA. A.; BARRETTO FILHO. H. Antropologia e Identificação. Os antropólogos e a identificação de terras indígenas no Brasil, 1977-2002. ContraCapa: Rio de Janeiro, 2004. pp. 9-29. 